\title{
THE RELATIONSHIP OF SALIVA CORTISOL LEVELS WITH STRESS LEVEL OF ANESTHESIOLOGY AND INTENSIVE CARE OFFACULTY OF MEDICINE AIRLANGGA UNIVERSITY IN THE ERA OF THE COVID-19 PANDEMIC
}

\author{
Ardi Gustian $^{1}$, Anna Surgean ${ }^{2}$, Arie Utariani ${ }^{3}$ \\ ${ }^{1-3}$ Anesthesiology and Intensive Care Department Faculty of Medicine Universitas Airlangga \\ Surabaya 60286 Indonesia \\ *Corresponding Author: Anna Surgean \\ Anesthesiology and Intensive Care Department Faculty of Medicine Universitas Airlangga \\ Surabaya 60286 Indonesia \\ surgeanunair@gmail.com
}

\begin{abstract}
Background: Residents' lives in the world of health are often accompanied by stressful conditions, where this is triggered by the specialist medical education program activities that are being undertaken by the anesthesiologist. The COVID-19 pandemic has resulted in an increase in the condition of anesthesiology residents at various educational centers in Indonesia. Including one that happened in Surabaya, to be precise at the Soetomo Hospital. It is known that the higher the level of stress experienced by a person, this can also increase the level of cortisol in the individual's blood. Therefore, this study was structured to analyze the relationship of saliva cortisol levels with stress level of anesthesiology and intensive care of faculty of medicine Airlangga University in the era of the COVID-19 pandemic. Methods: This study was an analytic observational study through a cross sectional design which was measured by the Depression, Anxiety, and Stress Scale (DASS)-42 and their relationship to salivary cortisol levels. Results: The results showed that salivary cortisol levels of the Anesthesiology and Intensive Care FK UNAIR residents before entering the RIK stagnation cycle versus 2 weeks of running the RIK stagnation cycle with a median value of $0.315 \mathrm{~g} / \mathrm{dL}$ compared to $0.422 \mathrm{~g} / \mathrm{dL}$ with $(95 \% \mathrm{CI}, 0.143,0.778) \mathrm{g} / \mathrm{dL}$ versus $(95 \% \mathrm{CI}, 0.179,2.802) \mathrm{g} / \mathrm{dL}$ with $\mathrm{p}<0.05$. From the results of the DASS-42 questionnaire obtained 2 subjects $(5.7 \%)$ mild depression, 1 subject (2.9\%) moderate depression, 5 subjects $(14.3 \%)$ mild anxiety, 1 subject $(2.9 \%)$ moderate anxiety, 1 subject $(2,9)$. \%) severe anxiety, 2 subjects $(5.7 \%)$ mild stress, 5 subjects $(14.3 \%)$ moderate stress, 1 subject $(2.9 \%)$ severe stress. Conclusion: Thus, it can be concluded that the stress level of the anesthesiology resident participants in the COVID19 Pandemic era was not stressful or normal because almost $80 \%$ of the subjects did not experience stress.
\end{abstract}

Keywords: stress; cortisol; salivary cortisol; COVID-19 pandemic; Anesthesiology resident participants.

\section{Main text}

\section{1) Introduction}

Stress in the resident's professional life can be triggered by ongoing specialist medical education program activities (Harrison \& Stephens, 2019). This is because they themselves are expected to have abilities from various aspects such as clinical, academic, physical, and social aspects. They are even required to have 80 hours of work per week. In the world of health education, it is known that residency education is a professional education that is known to be difficult and stressful. Of course, this can provide various kinds of side effects, such as fatigue and stress, without exception anesthesiology (Simpkin et al., 2018).

A survey in the United States was conducted on the anesthesiology population, in which the study showed a fairly high level of fatigue in $41 \%$ of respondents and depression in $22 \%$ of respondents (Sun et al., 2019). Even compared to anesthesiologists who practice, it is known that resident anesthesiologists actually have a tendency to substance abuse to suicide (Fry et al., 2015). This condition also causes burnout due to stress with an estimated prevalence of between $30 \%$ to more than 54\% (Shanafelt et al., 2015).

Anesthesiologists themselves are known as one of the professions with a high workload (Slagle et al., 2018). One of them is that they are asked to think and act quickly and precisely. It is not surprising that later cases were found that the residents experienced fatigue and lack of sleep which led

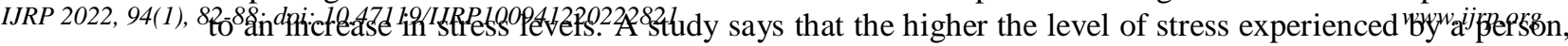


the higher the level of cortisol in the individual's blood. This is because cortisol levels have an independent daily circadian rhythm with the highest concentration in the morning and the lowest in the evening (Grosser et al., 2021).

Currently, the whole world is being hit by the COVID-19 pandemic, a virus that attacks the human respiratory organs and can cause shortness of breath and even lead to death (Zhang, 2021). This disease infection is caused by a new type of corona virus, namely the novel Corona viridae-2. Through data from the Task Force for the Acceleration of Handling Covid-19 in Indonesia in mid-2020, 16,496 confirmed cases of COVID-19 were obtained with 490 new cases, of which 1,076 people were declared dead (O'Byrne et al., 2021).

The stress level of health workers is also known to be caused by the COVID-19 pandemic (Talaee et al., 2020). In fact, this condition shows that there is a figure of $25 \%$ for health workers at the level of stress they experience (Windarwati et al., 2021). It is known that frontline medical personnel actually have the highest risk of symptoms of depression (OR, 1.52; 95\% CI, $1.11-2.09 ; \mathrm{P}=0.01$ ), anxiety (OR, 1.57; 95\% CI , $1.22-2.02$; P 0.001), insomnia (OR , 2.97; 95\% CI, $1.92-4.60$; P < 0.001 ), and sadness (OR, 1.60; 95\% CI, $1.25-2.04$; P < 0.001) (Brooks, 2020).

Several stress scales are also used to determine the level of stress experienced by a person, such as PSS-10, KPDS-10, and DASS-42. In addition, to analyze a person's stress level, several scales are also used. However, researchers in this analysis used the Depression, Anxiety, and Stress Scale (DASS) approach. used to measure a person's negative emotional state, namely depression, anxiety, and stress (Kusumadewi \& Wahyuningsih, 2020). The DASS measurement aims to determine and assess the level and core symptoms of depression, anxiety and stress, where it is known that as many as 14 items relate to symptoms of depression, 14 items relate to symptoms of anxiety, and 14 items relate to symptoms of stress.

Therefore, this study was compiled to analyze the relationship of saliva cortisol levels with stress level of anesthesiology and intensive care of faculty of medicine Airlangga University in the era of the COVID-19 pandemic. Then, the relationship between salivary cortisol levels and stress. Evaluation of stress levels was measured using the Depression, Anxiety, and Stress Scale (DASS) questionnaire

2) Method

This study is an observational analytic study with a cross sectional design to determine the level of stress in resident participants in Anesthesiology and Intensive Care, Faculty of Medicine Universitas Airlangga Surabaya in the COVID-19 pandemic era measured using the Depression, Anxiety, and Stress Scale (DASS)-42 and its relationship with levels of salivary cortisol. This research was conducted in RSUD Soetomo Surabaya in the middle of 2021 after obtaining approval from the Ethics Commission of RSUD Soetomo Surabaya, Indonesia.

The population is all resident participants of Anesthesiology and Intensive Care Faculty of Medicine UNAIR who are studying at RSUD Soetomo and worked in a special isolation room (RIK) in the middle of 2021. The sample studied was an affordable population that met the inclusion criteria.

The presentation of the data in this study is arranged in the form of tabulations and text/writings that clarify graphs/diagrams. In addition, statistical analysis used in this study was observational crosssectional analysis, SPEARMAN correlation statistical test, degree of significance of $=0.01(\mathrm{p}<0.01)$, and calculations using SPSS software computer program.

3) Result

\section{Demographic Characteristics of Research Subjects}

The results of the research conducted showed that from a total of 35 subjects there were 30 men and 5 women with demographic data. For ages less than 30 years and more than or equal to 30 years are 14 people (40\%) and 21 people (60\%). Thus, the age of more than or equal to 30 years tends to be more dominant in this study. The marital status listed in the results of this study are 16 married people and 19 unmarried people. Furthermore, the demographic data at the semester level shows the results of semester 2 as many as 1 person, semester 3 is 8 people, semester 5 is 5 people, semester 6 is 6 people, semester 7 is 5 people, semester 8 is 6 people, and 9 people are 4 people. Thus, the 3 rd semester residents tend to dominate in this study, while the least is the 2nd semester. Furthermore, BMI status shows the results that normal, overweight, obesity grade 1, and obesity grade 2 are as follows, 14 people (40\%), 4 people (11.4\%), 16 people (45.7\%), and 1 person $(2.9 \%)$. 
Description of Depression, Anxiety, and Stress of Anesthesiology Residents Participant, Faculty of Medicine UNAIR

In this study, the stress level of the subject was also assessed, which was measured using the DASS-42 scale. The results were then divided into 3 categories namely, depression, anxiety, and stress and each category was grouped into normal, mild, moderate, and severe degrees.

Tabel 1. Depression, Anxiety, and Stress of Anesthesiology Residents Participant, Faculty of

\begin{tabular}{|c|c|c|}
\hline \multicolumn{3}{|c|}{ Medicine UNAIR } \\
\hline Variable & & $\mathrm{n}(\%)$ \\
\hline \multicolumn{3}{|l|}{ Depression } \\
\hline Min-max & $0-22$ & \\
\hline Median & 3 & \\
\hline Normal & & $32(91,4 \%)$ \\
\hline Mild & & $2(5,7 \%)$ \\
\hline Moderate & & $1(2,9 \%)$ \\
\hline Severe degrees & & $0(0 \%)$ \\
\hline \multicolumn{3}{|l|}{ Anxiety } \\
\hline Min-max & $0-17$ & \\
\hline Median & 5 & \\
\hline Normal & & $28(80 \%)$ \\
\hline Mild & & $5(14,3 \%)$ \\
\hline Moderate & & $1(2,9 \%)$ \\
\hline Severe degrees & & $1(2,9 \%)$ \\
\hline \multicolumn{3}{|l|}{ Stress } \\
\hline Min-max & $1-20$ & \\
\hline Median & 5 & \\
\hline Normal & & $27(77,1 \%)$ \\
\hline Mild & & $2(5,7 \%)$ \\
\hline Moderate & & $5(14,3 \%)$ \\
\hline Severe degrees & & $1 \quad(2,9 \%)$ \\
\hline
\end{tabular}

Through research, it was found that mild and moderate levels of depression were found in 2 people $(5.7 \%)$ and 1 person $(2.9 \%)$ with a median score of 3 . The remaining 32 people $(91.4 \%)$ were in the poor category. condition. normal. The levels of mild, moderate, and severe anxiety were found in 5 people $(14.3 \%), 1$ person $(2.9 \%)$, and 1 person $(2.9 \%)$ with a median value of 5 . The remaining 28 people were declared normal. But there were 2 people $(5.7 \%), 5$ people $(14.3 \%)$, and 1 person $(2.9 \%)$ with a median value of 5 . The remaining 27 people were in normal condition. 


\section{Description of Saliva Cortisol Levels for Anesthesiology Residents Participant, Faculty of Medicine UNAIR}

From the study, it was found that the median salivary cortisol levels of the Anesthesiology and Intensive Care FK UNAIR residents before entering the RIK stagnation cycle and 2 weeks of the RIK stagnation cycle running were 0.315 and $0.422 \mathrm{~g} / \mathrm{dL}$ with the min-max values being $0.143-0.778$ and $0.179-2.802 \mathrm{~g} / \mathrm{dL}$. Although the median value was at normal value, there were samples that had cortisol values above normal after 2 weeks of RIK stagnation. Thus, it was found that there was an increase in salivary cortisol levels before entering the RIK stage with 2 weeks of running the RIK stage.

Comparative Analysis of Cortisol Values Between Before RIK Stage and 2 Weeks Running RIK Stage

From this study, the results of the comparative analysis of salivary cortisol values were obtained between before the RIK stage and two weeks of the RIK stage. Tests for changes in cortisol levels before stagnation RIK with 2 weeks of running stagnation RIK were tested using the Wilcoxon test because cortisol data before stagnation RIK and 2 weeks of stagnation RIK were declared abnormal. Through the Wilcoxon test, obtained a value of 0.002 where the value is $<0.05$. This indicates that there is a difference in the value of cortisol levels before RIK stagnation with 2 weeks when running RIK stagnation.

Analysis of the Relationship between Depression, Anxiety, and Stress with Cortisol Levels for Resident Participants in Anesthesiology and Intensive Care, Faculty of Medicine UNAIR

In this study, an analysis was also carried out to see the relationship between depression, anxiety, and stress with cortisol levels in the resident participants of Anesthesiology and Intensive Care Faculty of Medicine UNAIR/Soetomo Hospital Surabaya. It is known that the correlation test (relationship) was tested using the Spearman test in the form of an ordinal and cortisol level data. Based on the results of the Spearman test, it was found that the p-value of depression was 0.065 , anxiety was 0.449 , and stress was 0.274 , where the value is $>0.05$ which means there is no relationship between depression, anxiety, and stress with cortisol levels before RIK status in resident participants. Anesthesiology and Intensive Care Faculty of Medicine UNAIR Surabaya.

While testing the relationship between depression, anxiety, and stress with cortisol levels 2 weeks of walking RIK was tested using the Spearman correlation test because data on anxiety, depression and stress were in ordinal form and data on cortisol levels for 2 weeks of walking RIK was declared abnormal, based on the results of the Spearman test, p- the value of depression is 0.341 , anxiety is 0.659 , and stress is 0.943 where the value is $>0.05$ which means there is no relationship between depression, anxiety, and stress with cortisol levels stagnation 2 weeks RIK running in Resident Anesthesiology and Intensive Care Participants, Faculty of Medicine UNAIR Surabaya.

4) Discussion

This study analyzed the salivary cortisol levels in resident participants of Anesthesiology and Intensive Care, Faculty of Medicine UNAIR who were undergoing a stagnation round at RIK-1 RSUD Soetomo Surabaya. From the research, it was found that the salivary cortisol levels of resident participants Anesthesiology and Intensive Care, Faculty of Medicine UNAIR before entering the RIK stagnation cycle and 2 weeks of running RIK stagnation cycles with median values of 0.315 and 0.422 $\mathrm{g} / \mathrm{dL}$ with min-max values were $0.143-0.778$ and $0.179-2.802 \mathrm{~g} / \mathrm{dL}$. There was an increase in salivary cortisol levels before entering the RIK stage with 2 weeks of the RIK stage running. The test for changes in cortisol levels before RIK stagnation with 2 weeks of running RIK stagnation was tested using the Wilcoxon test because the cortisol data before RIK stagnation and 2 weeks of running RIK stagnation were declared abnormal, based on the results of the Wilcoxon test, a p-value of 0.002 was obtained where the value was $<0.05$ which means there is a difference in the value of cortisol levels before RIK stagnation with 2 weeks of running RIK stagnation where there is an increase in cortisol levels between before RIK stagnation and 2 weeks of running RIK stagnation.

Based on the results of the Spearman correlation test in this study, it was found that the RIK stagnation rate with depression was 0.065 , anxiety was 0.449 , and stress was 0.274 . This value shows that there is no relationship between depression, anxiety, and stress with cortisol levels before RIK stagnation in anesthesia participants at Airlangga University. Likewise, the p-value between salivary cortisol levels after 2 weeks of RIK stagnation cycle with depression 0.341 , anxiety 0.659 , and stress 0.943 which indicates there is no relationship between depression, anxiety, and stress with cortisol levels of anesthesiology participants at Universitas Airlangga. This condition is different from the research conducted by Andre et al (2021), that in the research conducted, it was found that there was a relationship between cortisol levels and stress levels. 
On the other hand, this study also analyzed the level of stress experienced by anesthesiology participants at Airlangga University, where a stress analysis was carried out using the DASS-42 questionnaire consisting of 42 items. Through these 42 items, it is known that as many as 14 questions relate to symptoms of depression, 14 items relate to symptoms of anxiety, and 14 items relate to symptoms of stress (Ozamiz-Etxebarria et al., 2020). In this study, there were 2 people (5.7\%) and 1 (2.9\%) with a median score of 3 . The remaining 32 people $(91.4 \%)$ were in normal condition. The levels of mild, moderate, and severe anxiety were found in 5 people (14.3\%), 1 person (2.9\%), and 1 person $(2.9 \%)$ with a median score of 5 . The remaining 28 people $(80 \%)$ is normal. There were 2 people (5.7\%), 5 people (14.3\%) and 1 person (2.9\%) with a median score of 5. The remaining 27 people $(77.1 \%)$ under normal conditions. Compared to previous studies, this study found much different results. One of them is the research conducted by Andre, et al (2021) on 40 Anesthesia residents at RSUD Dr. Soetomo Surabaya with an age range of 28-39 years, the results showed that the PPDS participants who experienced mild and moderate stress were 25 people $(62.5 \%)$ and 15 people (37.5\%) (Kurniawan \& Utariani, 2021).

Furthermore, as a note for researchers, that this study took place as the second wave of attacks of the new delta COVID-19 variant began, where almost all participants had undergone health procedures through the COVID-19 protocol until they more or less understood the procedures and behavior in treating COVID-19 patients. -19 according to the existing standards in RIK-1. This may be the cause of the reduced level of stress experienced by the participants, because at least some of them have understood the situation and conditions being faced (Spinelli et al., 2020).

\section{5) Conclusion}

From this study, it can be concluded that the stress level in Anesthesiology Residents Participant in the COVID-19 Pandemic era was not stressful or normal because almost $80 \%$ of the subjects did not experience stress. There is no significant relationship between salivary cortisol levels and stress levels.

\section{Acknowledgements}

The author expresses his deepest gratitude to Universitas Airlangga. The author would also like to thank parents, lecturers, and friends for their support and encouragement during this research. 


\section{References}

Brooks, M. (2020). COVID-19: Striking'Rates of Anxiety. Depression in Healthcare Workers.

Fry, R. A., Fry, L. E., \& Castanelli, D. J. (2015). A retrospective survey of substance abuse in anaesthetists in Australia and New Zealand from 2004 to 2013. Anaesthesia and Intensive Care, 43(1), 111-117.

Grosser, L., Knayfati, S., Yates, C., Dorrian, J., \& Banks, S. (2021). Cortisol and shiftwork: A scoping review. Sleep Medicine Reviews, 101581.

Harrison, M. A., \& Stephens, K. K. (2019). Shifting from wellness at work to wellness in work: Interrogating the link between stress and organization while theorizing a move toward wellness-in-practice. Management Communication Quarterly, 33(4), 616-649.

Kurniawan, A., \& Utariani, A. (2021). Hubungan Antara Tingkat Stres dan Kadar Kortisol Saliva dan Faktor Penyebab Stres Residen Anestesiologi dan Terapi Intensif pada Era Pandemi Covid-19. Jurnal Syntax Transformation, 2(2), 147-156.

Kusumadewi, S., \& Wahyuningsih, H. (2020). Model Sistem Pendukung Keputusan Kelompok untuk Penilaian Gangguan Depresii, Kecemasan dan Stress Berdasarkan DASS-42. Jurnal Teknologi Informasi Dan Ilmu Komputer, 7(2), 219-228.

O’Byrne, L., Gavin, B., Adamis, D., Lim, Y. X., \& McNicholas, F. (2021). Levels of stress in medical students due to COVID-19. Journal of Medical Ethics, 47(6), 383-388.

Ozamiz-Etxebarria, N., Dosil-Santamaria, M., Picaza-Gorrochategui, M., \& Idoiaga-Mondragon, N. (2020). Stress, anxiety, and depression levels in the initial stage of the COVID-19 outbreak in a population sample in the northern Spain. Cadernos de Saude Publica, 36.

Shanafelt, T. D., Hasan, O., Dyrbye, L. N., Sinsky, C., Satele, D., Sloan, J., \& West, C. P. (2015). Changes in burnout and satisfaction with work-life balance in physicians and the general US working population between 2011 and 2014. Mayo Clinic Proceedings, 90(12), 1600-1613.

Simpkin, A. L., Khan, A., West, D. C., Garcia, B. M., Sectish, T. C., Spector, N. D., \& Landrigan, C. P. (2018). Stress from uncertainty and resilience among depressed and burned out residents: a cross-sectional study. Academic Pediatrics, 18(6), 698-704.

Slagle, J. M., Porterfield, E. S., Lorinc, A. N., Afshartous, D., Shotwell, M. S., \& Weinger, M. B. (2018). Prevalence of potentially distracting noncare activities and their effects on vigilance, workload, and nonroutine events during anesthesia care. Anesthesiology, 128(1), 44-54.

Spinelli, M., Lionetti, F., Pastore, M., \& Fasolo, M. (2020). Parents' stress and children's psychological problems in families facing the COVID-19 outbreak in Italy. Frontiers in Psychology, 11, 1713.

Sun, H., Warner, D. O., Macario, A., Zhou, Y., Culley, D. J., \& Keegan, M. T. (2019). Repeated cross-sectional surveys of burnout, distress, and depression among anesthesiology residents and first-year graduates. Anesthesiology, 131(3), 668-677.

Talaee, N., Varahram, M., Jamaati, H., Salimi, A., Attarchi, M., Kazempour Dizaji, M., Sadr, M., Hassani, S., Farzanegan, B., \& Monjazebi, F. (2020). Stress and burnout in health care workers during COVID-19 pandemic: validation of a questionnaire. Journal of Public Health, 1-6.

Windarwati, H. D., Ati, N. A. L., Paraswati, M. D., Ilmy, S. K., Supianto, A. A., Rizzal, A., Sulaksono, A. D., Lestari, R., \& Supriati, L. (2021). Stressor, coping mechanism, and motivation among health care workers in dealing with stress due to the COVID-19 pandemic in Indonesia. Asian Journal of Psychiatry, 56, 102470.

Zhang, H. (2021). Recent epidemics and their impact on the society: COVID-19, SARS, MERS, H1N1. E3S Web of Conferences, 308. 
